\title{
Molar Conductivities of monomethylammonium double sulphates of Cobalt, Nickel and Copper at $25^{\circ} \mathrm{C}$.
}

\author{
A.Tharani ${ }^{1}$, Revathy Rajagopal ${ }^{2}$ \\ ${ }^{1}$ Department of Chemistry, Stella Maris College (Autonomous), India.. \\ ${ }^{2}$ Department of Chemistry, 17, Cathedral Road, Stella Maris College (Autonomous), Chennai - 600086, India.
}

\begin{abstract}
The double sulphates of copper, nickel and cobalt with monomethylammonium cation were synthesized as reported in literature. The synthesized double sulphates of copper, cobalt and nickel with mono methyl ammonium cation were characterized using FTIR. The characteristic bands for $\mathrm{N}-\mathrm{H}, \mathrm{C}-\mathrm{H}, \mathrm{SO}_{4}^{2-}$ for these compounds reported in literature were observed by the synthesized double salts. High conductivities of double salts were indicative of their strong electrolytic nature. These data will be useful when these compounds have to be grafted onto mesoporous materials for catalytic studies.
\end{abstract}

Keywords: conductivity studies, double sulphates, monomethylammonium double sulphates

\section{Introduction}

Recently, great interest has been shown in the field of syntheses of double sulphates with nonmetallic cations. A lot of data was reported by Jordanovska, $\mathrm{V}$ and others [1-5] on double sulphates of divalent, trivalent and rare earths metals with many non-metallic cations. Their group extensively reported the crystal structure, complete analysis vibrational spectra of single crystals, XRD and thermal analysis of the above salts. There was no data concerning the conductivity of these double salts. So it was thought worthwhile to analyze the conductivity of few transition metal double sulphates with powder diffraction data ${ }^{1}$ of the double sulphates reported in literature show that cobalt, monomethyl ammonium cation in the present paper. Literature survey reveals the study of thermal decomposition, complete IR interpretation and crystal structure of divalent metal $(\mathrm{Co}, \mathrm{Ni}$ and $\mathrm{Cu})$ double sulphates with monomethylammonium cation. The $\mathrm{X}$-ray nickel and zinc salts are iso structural whereas copper double sulphates has a different structure. Both the structures belong to triclinic system with $Z=1$.

\subsection{Synthesis of monomethylammonium sulphate}

\section{Experimental}

Aqueous solution of the mono ammonium sulphate was prepared by stepwise neutralization of methyl amine (Laboratory Reagent $40 \%$ solution) with dilute sulphuric acid (A.R grade) $(\approx 1 \mathrm{~N})$ to $\mathrm{pH} 4-5$. The resultant monomethylammonium sulphate was then diluted to standard volume $100 \mathrm{~cm}^{3}$.

\subsection{Synthesis of double sulphates of Cobalt, Nickel and Copper with MonoMethylAmmonium Sulphates [MMAS]}

Aqueous solutions of respective transition metal sulphates (A.R grade) and MMAS were mixed in the molar ratio of 1: 3 as reported in literature [1] The resultant mixtures were concentrated to a small volume (5$8 \mathrm{~cm}^{3}$ ) on a steam bath. Dry ethanol was added to this solution after it attained room temperature. The resultant precipitated product was filtered, washed with $95 \%$ ethanol and dried over silica gel. The composition of the dried products was then fixed [6]. All the synthesized double sulphates were stored, after powdering, in a dessicator over silica gel.

\subsection{IR studies}

The spectrum of the sample was recorded on ABBMB 3000 Fourier transform infra red (FTIR) spectrometer in the region 4000 to $500 \mathrm{~cm}^{-1}$. In this technique, the samples surface is contacted with a crystal surface such as germanium. The spectra were performed with the resolution of $16 \mathrm{~cm}^{-1}$ and recorded at $45^{\circ}$ incident angle using Zinc selenide crystal plate. 


\subsection{Conductivity Studies}

Digital conductivity meter, model: RI 503 was used to measure the conductivity. The cell constant was determined using a standard solution of $0.0100 \mathrm{~mol} / \mathrm{cm}^{3}$ potassium chloride $(\mathrm{KCI})$. The limiting conductivity of water at $298 \mathrm{~K}$ was found to be $0.034 \mathrm{mS} \mathrm{cm}^{-1}$.

\section{Results And Discussion}

The composition of the synthesized double salts was fixed from the results of metal analysis complexometrically and sulphate gravimetrically. Table 1 shows the same.

Table 1: Results for the chemical composition of $\operatorname{MMAM}^{1} S$ where $\mathbf{M}^{1}=$ cobalt, nickel and copper

\begin{tabular}{|l|l|l|l|l|l|}
\hline \multirow{2}{*}{ Compound } & \multicolumn{2}{|c|}{$\% \mathbf{M}$} & \multicolumn{2}{c|}{ \% SO} & \multirow{2}{*}{ Empirical formula } \\
\cline { 2 - 6 } & Theor. & Exp. & Theor. & Exp. & \\
\hline CoMMAS (1:3) & 13.95 & 13.7 & 40.848 & 39.5 & $\left(\mathrm{CH}_{3} \mathrm{NH}_{3}\right)_{2} \mathrm{Co}\left(\mathrm{SO}_{4}\right)_{2} \cdot 6 \mathrm{H}_{2} \mathrm{O}$ \\
\hline NiMMAS (1:3) & 13.17 & 13.0 & 38.6014 & 37.3 & $\left(\mathrm{CH}_{3} \mathrm{NH}_{3}\right)_{2} \mathrm{Ni}_{(}\left(\mathrm{SO}_{4}\right)_{2} \cdot 6 \mathrm{H}_{2} \mathrm{O}$ \\
\hline CuMMAS (1:3) & 14.85 & 14.8 & 39.9521 & 38.7 & $\left(\mathrm{CH}_{3} \mathrm{NH}_{3}\right)_{2} \mathrm{Cu}\left(\mathrm{SO}_{4}\right)_{2} \cdot 6 \mathrm{H}_{2} \mathrm{O}$ \\
\hline
\end{tabular}

The infrared spectra of these compounds showed peaks characteristic of coordinated water, N-H, C-H, $\mathrm{C}-\mathrm{N}$ and $\mathrm{O}-\mathrm{H}$ stretching and bending bands as reported in literature.

The solutions of different concentrations of double sulphates were prepared in conductivity water and their conductivities were measured. The Tables 2, 3, and 4 show the conductivity data of Copper, Cobalt and Nickel double salts respectively.

From the conductivity of solutions, conductivity of salt was obtained by equation 1:

$\kappa_{\text {Salt }}=\kappa_{\text {Soln }^{-}} \kappa_{\text {water } \ldots \ldots \ldots \ldots \ldots \ldots \ldots \ldots \ldots \ldots \ldots \ldots \ldots \ldots \ldots \ldots \ldots \ldots}$

Table 2: The limiting ionic conductivities value for the CuMMAS at $25^{\circ} \mathrm{C}$

\begin{tabular}{|c|c|c|c|c|c|}
\hline $\begin{array}{l}\text { C Gram } \\
\text { equivalents } \\
\text { /dm }^{3}\end{array}$ & $\begin{array}{l}\square \text { Soln } \\
\mathbf{m S ~ c m}^{-1}\end{array}$ & $\begin{array}{l}\square \text { Salt }=\square \text { Soln- }^{-} \square \\
\text { water } \\
\text { mScm }^{-1}\end{array}$ & $\square /\left(\mathbf{m S c m}^{2} \mathbf{m o l}^{-1}\right)$ & $\square \mathbf{c}$ & $\square_{0}^{\prime}$ \\
\hline 0.01 & 5.3727 & 5.3387 & 533870 & 0.1 & 796821.3119 \\
\hline 0.005 & 3.0427 & 3.0087 & 601740 & 0.07011 & 784890.7056 \\
\hline 0.0025 & 1.6827 & 1.6487 & 659480 & 0.05 & 789796.5743 \\
\hline 0.00125 & 0.9027 & 0.8687 & 694960 & 0.035355 & 786752.5829 \\
\hline 0.000625 & 0.4627 & 0.4287 & 685920 & 0.025 & 747596.8063 \\
\hline
\end{tabular}

Table 3: The limiting ionic conductivities value for the CoMMAS at $25^{\circ} \mathrm{C}$

\begin{tabular}{|l|l|l|l|l|l|}
\hline $\begin{array}{l}\text { C Gram } \\
\text { equivalents } \\
\mathbf{/ d m}^{\mathbf{3}}\end{array}$ & $\begin{array}{l}\square \text { Soln } \\
\mathbf{m S ~ c m}^{-1}\end{array}$ & $\begin{array}{l}\square \text { Salt }=\square \text { soln }^{-} \\
\text {water } \\
\mathbf{m S c m}^{-1}\end{array}$ & $\square /\left(\mathbf{m S c m}^{\mathbf{2}} \mathbf{m o l}^{\mathbf{- 1}}\right)$ & $\square \mathbf{c}$ & $\square$ \\
\hline 0.01 & 6.4127 & 6.3787 & 637870 & 0.1 & 763916.4156 \\
\hline 0.005 & 3.6027 & 3.5687 & 713740 & 0.07011 & 808013.6434 \\
\hline 0.0025 & 2.0127 & 1.9787 & 791480 & 0.05 & 862648.6142 \\
\hline 0.00125 & 1.1227 & 1.0887 & 870960 & 0.035355 & 924915.7257 \\
\hline 0.000625 & 0.6227 & 0.5887 & 941920 & 0.025 & 982445.9471 \\
\hline 0.0003125 & 0.3527 & 0.3187 & 1019840 & 0.017678 & 1050481.208 \\
\hline
\end{tabular}

Table 4: The limiting ionic conductivities value for the NiMMAS at $25^{\circ} \mathrm{C}$

\begin{tabular}{|c|c|c|c|c|c|}
\hline $\begin{array}{l}\text { C } \\
\text { equivalents } \\
/ \text { dm }^{3}\end{array}$ & $\begin{array}{l}\square \text { Soln } \\
\text { mS cm }^{-1}\end{array}$ & $\begin{array}{l}\square \text { Salt }=\square \text { Soln- }^{-} \square \\
\text { water } \\
\text { mScm }^{-1}\end{array}$ & $\square /\left(\mathbf{m S c m}^{2} \mathbf{m o l}^{-1}\right)$ & $\square \mathbf{c}$ & $\square_{0}^{\prime}$ \\
\hline 0.01 & 6.4927 & 6.487 & 645870 & 0.1 & 768893.1756 \\
\hline 0.005 & 3.5627 & 3.5287 & 705740 & 0.07011 & 795771.9156 \\
\hline 0.0025 & 1.9127 & 1.8787 & 751480 & 0.05 & 816826.2337 \\
\hline 0.00125 & 1.0427 & 1.0087 & 806960 & 0.035355 & 855345.2665 \\
\hline 0.000625 & 0.5527 & 0.5187 & 829920 & 0.025 & 864500.0703 \\
\hline 0.0003125 & 0.3027 & 0.2687 & 859840 & 0.017678 & 884868.3727 \\
\hline
\end{tabular}

Three different plots were drawn namely, Concentration C verses molar conductivity $\Lambda_{\mathrm{m}}$, 
$\sqrt{ } \mathrm{C}$ verses molar conductivity $\Lambda$ and $\sqrt{\mathrm{C}}$ verses $\Lambda_{\mathrm{o}}$ '.

Plots of molar conductivity of different double sulphates verses concentration showed that molar conductivity $\lambda_{c}$ increases with decrease in concentration proving that the synthesized compounds are ionic in nature. ( strong electrolytes).

The graph obtained for the value of $\lambda \mathrm{m}$ versus concentration is shown Figure 1 below:

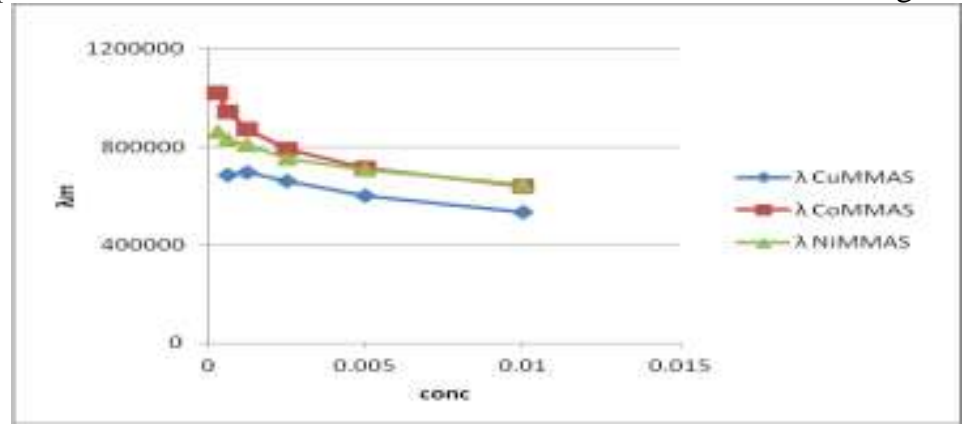

Fig 1: $\square_{m}$ versus concentration

Figure 2 shows the of $\lambda m$ versus $\sqrt{ } \mathrm{C}$



Fig 2: $\square \mathbf{m}$ versus $\square \mathbf{C}$

According to Debye Hŭ ckel Onsager theory the equivalent conductance of a dilute solution of strong electrolyte is a linear function of the square root of the concentration.

The limiting law may be written as:

$\lambda_{\mathrm{c}}=\lambda_{\mathrm{o}}-\left(\mathrm{A}+\mathrm{B} \lambda_{\mathrm{o}}\right) \sqrt{\mathrm{C}} \ldots \ldots \ldots \ldots \ldots \ldots \ldots . . \ldots \ldots \ldots \ldots$



$\mathrm{C}=$ concentration gram equivalents $/ \mathrm{dm}^{3}$

$\mathrm{A}=$ numerical constant which is a function of the temperature, viscosity and dielectric constant of the solvent

$\mathrm{B}=$ numerical constant which is a function of the temperature and dielectric constant of the solvent.

Both $\mathrm{A}$ and $\mathrm{B}$ also depend on the valence type of the electrolyte and the relative mobilities of anion and cation.

A plot of equivalent conductance of the double salts under study against the square root of the normality is shown in Figures 8-10. It is seen that curves obtained are not linear. This type of deviation from theory has been found to be characteristic of strong electrolytes.

To compute the best value of the limiting conductance, we have used the method of Shedlovsky [7]. The Onsager equation on rearrangement gives,

$\lambda_{0}=\underline{\lambda+\mathrm{A} \sqrt{\mathrm{C}}}$ ...4

$1-\mathrm{B} \sqrt{\mathrm{C}}$

Where $\lambda_{0}{ }^{\prime}$ is written in place of $\lambda_{0}$. It is found that $\lambda_{0}{ }^{\prime}$ is not a constant and is a function of the concentration.. Therefore a plot of $\lambda_{0}$ ivs C will give a straight line which may be extrapolated to zero concentration to find $\lambda_{0}$. The plots of of $\lambda_{0}$ vs $\sqrt{ } \mathrm{C}$ obtained are shown in Figure 2: 


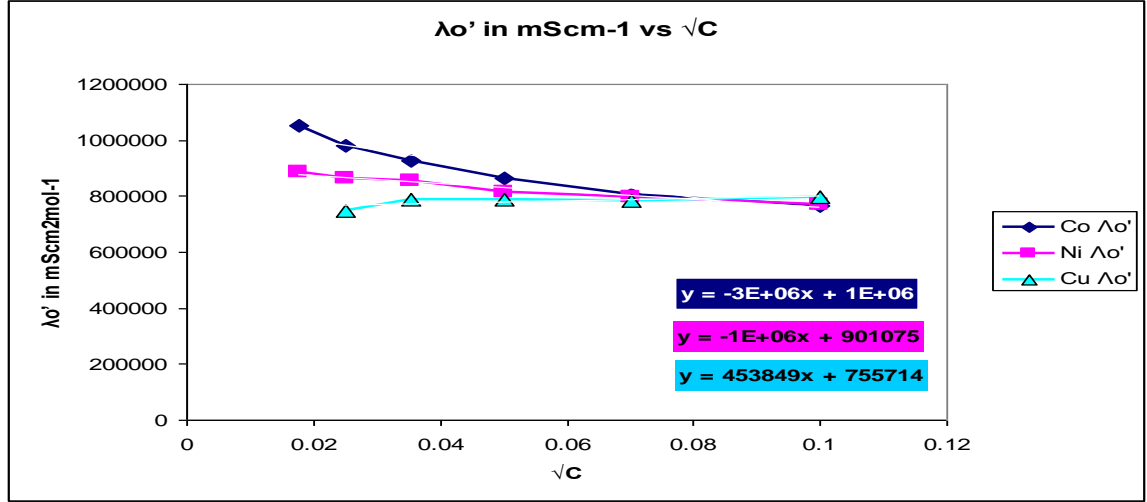

Fig 2: $\square_{0}^{\prime}$ versus $\square \mathrm{C}$

\section{Conclusion}

The synthesized double sulphates of copper, cobalt and nickel with mono methyl ammonium cation were characterized using FTIR. The characteristic bands for $\mathrm{N}-\mathrm{H}, \mathrm{C}-\mathrm{H}, \mathrm{SO}_{4}{ }^{2-}$ for these compounds reported in literature were observed by the synthesized double salts. High conductivities of double salts were indicative of their strong electrolytic nature. These data will be useful when these compounds have to be grafted onto mesoporous materials for catalytic studies.

\section{References:}

[1] Jordanovska, V., Aleksovska. S. and Siftar, J., J. Therm. Anal., 38, 1563-1570 (1992)

[2] Jordanovska, V. and Siftar, J., J. Therm. Anal., 39, 281-288 (1993)

[3] Jordanovska, V., Boyanov. B. and Pejov, Lj., J. Therm. Anal. Cal., 71, 629-634 (2003)

[4] Jordanovska, V., Boyanov, B. and Naumov, P., J. Therm. Anal. Cal., 62, 267- 275(2000)

[5] Jayasree, R.S. Nayor. V.U. and Jordanovska, V., Spectochim Acta, part A 65, 278-284(2006)

[6] J. Mendham, R.C. Denney, J.D. Barnes, M. Thomas, "Vogel's text book of quantitative Chemical Analysis" $6^{\text {th }}$ edition, 2005

[7] Shedlovsky, T. J. Am. Chem. Soc. 54, 54 (1932) 